\section{Incidence of neovascularization in the fellow eye of patients with unilateral retinal angiomatous proliferation}

C Campa, SP Harding, IA Pearce, NAV Beare, $\mathrm{MC}$ Briggs and $\mathrm{H}$ Heimann

\begin{abstract}
Aims The aim of this study is to describe the incidence and characteristics of neovascularization in the fellow eye of patients with retinal angiomatous proliferation (RAP).

Methods This is a retrospective study conducted on all patients with a diagnosis of unilateral RAP commencing treatment in a single centre between November 2002 and January 2010. Clinical biomicroscopic examination, fluorescein angiography, and if required, indocyanine green angiography, and optical coherence tomography were used to evaluate all patients.

Results In all, 37 patients had a follow-up of $\geqslant 1$ year, $28 \geqslant 2$ years, and $11 \geqslant 3$. Patients who developed RAP in the fellow eye were: 2 of $37(5.4 \%)$ within 1 year of follow-up, 4 of 28 (14.2\%) within 2 years, and 4 of $11(36.3 \%)$ within 3 years.

Conclusion In our case series, the risk of neovascularization in the fellow eye of patients with unilateral RAP increased with time. Approximately one-third of patients with a 3-year follow-up developed a bilateral disease. Our findings warrant further large-scale investigation.

Eye (2010) 24, 1585-1589; doi:10.1038/eye.2010.88; published online 11 June 2010
\end{abstract}

Keywords: RAP; fellow eye; choroidal neovascularization

\section{Introduction}

In 1992, Hartnett et $a l^{1}$ described for the first time a particular form of wet age-related macular degeneration (AMD) characterized by a deep retinal vascular anomalous complex. Subsequently, Yannuzzi et $a l^{2}$ proposed the term retinal angiomatous proliferation (RAP) to describe this distinct subgroup of neovascular AMD (nAMD). They identified three stages of the disease.

Stage 1 consists of capillary proliferation within the retina (intraretinal neovascularization); stage 2 is determined by the extension of the neovascularization into the sub-retinal space (sub-retinal neovascularization) and is associated with serous PED; in stage 3, retino-choroidal anastomosis and true choroidal new vessels are present (choroidal neovascularization, CNV).

RAP has been estimated to account for $12-15 \%$ of newly diagnosed $\mathrm{nAMD}^{3}$ and is believed to have a different natural course and response to therapy compared with standard CNV. ${ }^{4}$ A range of alternative treatment options have been reported in case series with limited evidence of efficacy. ${ }^{5-10}$ No randomized controlled data have been published to date; the prognosis of RAP is currently considered to be poor.

Gross et al ${ }^{11}$ have reported that, in patients with unilateral RAP, a neovascular event in the fellow eye occurs at an annual and accumulative rate that far exceeds that for other forms of nAMD, with a bilateral involvement in $100 \%$ of cases within 3 years.

These findings, although now considered well established, have not been confirmed by other authors yet. In this study, we aimed to assess the risk of neovascularization in the fellow eye of patients presenting with unilateral RAP.
St Paul's Eye Unit, Royal Liverpool University Hospital, Liverpool, UK

Correspondence: C Campa, St Paul's Eye Unit, Royal Liverpool University Hospital, Prescot Street, Liverpool L7 8XP, UK Tel: + 44 (0) 151706 3966; Fax: + 44 (0) 1517065905 E-mail: claudio.campa@ yahoo.com

Received: 18 March 2010 Accepted in revised form: 30 April 2010 Published online: 11 June 2010

This paper has been partially presented as a poster at the ARVO 2009 meeting 


\section{Materials and methods}

We performed a retrospective review of medical records of all patients commencing treatment for nAMD at the St Paul's Eye Unit, Clinical Eye Research Centre, Liverpool, UK, between November 2002 and January 2010 with a baseline diagnosis of unilateral RAP. Routine assessment at baseline included best-corrected visual acuity (BCVA) and contrast sensitivity using a full refraction protocol and recorded as letters read at $1 \mathrm{~m}$ on an Early Treatment Diabetic Retinopathy Study (ETDRS) chart and Pelli Robson chart, respectively; slit-lamp biomicroscopy and ophthalmoscopy; stereoscopic $30 / 35^{\circ}$ fluorescein angiography using either a Zeiss FF450plus digital camera (Carl Zeiss Meditec AG, Jena, Germany) or Heidelberg retina angiograph scanning laser ophthalmoscope (Heidelberg Engineering GmbH, Heidelberg, Germany).

Most of the patients also had indocyanine green angiography and optical coherence tomography (OCT) (STRATUS OCT - Carl Zeiss Meditec, Inc, Jena, Germany; 3D OCT-1000-Topcon Inc, Paramus, NJ, USA; SPECTRALIS OCT_-Heidelberg Engineering $\mathrm{GmbH})$.

Patients were followed 1-3 monthly according to their therapeutic regimen. At each follow-up visit, BCVA and slit examination were performed, together with OCT in the majority of patients. Fundus fluorescein angiography was typically carried out 3 monthly and in any case in which the retina specialist felt it necessary.

For the purpose of this study, all angiograms were independently reviewed by two ophthalmologists (CC and $\mathrm{HH}$ ) and two masked graders (DP and JD) of the Liverpool Reading Centre. Only cases with unanimous consensus in the diagnosis were included in the study.

\section{Results}

The clinical records of 141 patients with a diagnosis of RAP were reviewed.

In total, 52 subjects had a RAP in one eye and nonspecific end-stage disease in the fellow eye; an additional 52 were excluded from the study because of poor quality of angiograms or no consensus in the diagnosis in either eye. Altogether, 37 patients were diagnosed with unilateral RAP and no signs of neovascularization in the fellow eye at baseline. These were 7 males and 30 females, all Caucasian; their ages ranged from 58 to 89 years (mean 79.7). In all, 37 patients reached a follow-up of at least 1 year; 28 of at least 2 years, and 11 of $\geqslant 3$ years (Table 1 ). RAP lesions were classified as stage 1 in 12 subjects, stage 2 in 20, and stage 3 in 5 subjects. RAP was multifocal at presentation in 10 eyes.

In all, 12 patients were treated with verteporfin photodynamic therapy (VPDT), 13 with VPDT combined with intravitreal triamcinolone acetonide (IVTA), 10 with intravitreal ranibizumab, 1 with VPDT combined with IVTA and subsequently ranibizumab, and 1 with argon laser.

A neovascular lesion developed in the fellow eye as follows: 2 of $37(5.4 \%)$ within 1 year, 4 of $28(14.2 \%)$ within 2 years, and 4 of $11(36.3 \%)$ within 3 years. Other four patients had a bilateral involvement before the end of their fourth year of follow-up (Table 1). Overall, 10 cases had a bilateral lesion: the type of nAMD in the fellow eye was always a RAP. This was classified as stage 1 in four cases and at stage 2 in the other six.

No correlation was found between the stage of RAP at presentation in the first eye and in the fellow eye; the only patient with a multifocal RAP in the fellow eye had the same type of neovascular lesion (multifocal) in the first eye (Figure 1).

In four patients with bilateral involvement, the neovascular lesion in the fellow eye was in the same area of the fundus as in the first eye (Figure 2).

Among the 37 patients, the fellow eye had large drusen in 14 cases, pigment clumping in 29 , and areas of retinal pigment epithelium atrophy in 31. In all, 9 out of 10 patients who developed a bilateral lesion had retinal pigment epithelium atrophy and pigment clumping in the fellow eye before RAP development; 6 out of 10 had also large drusen (Table 1).

\section{Discussion}

During the last decade, RAP has been variously termed 'retinal vascular anomalous complex', 'occult chorioretinal anastomosis', 11 and 'type 3 neovascularization' ${ }^{3}$ For a long time it has been a matter of debate whether the initial neovascular process originated from the retinal ${ }^{2}$ or choroidal circulation. ${ }^{11}$

However, a recent histological study indicated that RAP stage 2 correlates histopathologically with a neovascular intraretinal angiomatous complex, without the presence of sub-retinal pigment epithelial neovascularization. ${ }^{12}$

This distinction between RAP and standard CNV is of clinical importance as there appear to be different responses to treatment for these two forms of neovascularization. ${ }^{4}$ RAP lesions have been excluded from the large, multicentre, randomized controlled trials of pegaptanib and ranibizumab.

Yannuzzi et $a l^{13}$ in a recent editorial have argued that RAP is an aggressive disease with a predictable symmetry and bilaterality. The same authors had previously shown in a consecutive series of 52 patients an incidence of bilateral involvement of $40 \%$ within 1 year, $56 \%$ within 2 years, and $100 \%$ within 3 years. ${ }^{10}$ 
Table 1 Demographic and clinical characteristics of patients

\begin{tabular}{|c|c|c|c|c|c|c|c|}
\hline \multirow[t]{2}{*}{ Patient } & \multirow{2}{*}{$\begin{array}{l}\text { Age } \\
\text { (years) }\end{array}$} & \multirow{2}{*}{$\begin{array}{c}\text { Length of } \\
\text { follow-up (days) }\end{array}$} & \multirow{2}{*}{$\begin{array}{l}\text { Treatment in } \\
\text { the first eye }\end{array}$} & \multirow{2}{*}{$\begin{array}{c}\text { Time before RAP development } \\
\text { in the fellow eye (days) }\end{array}$} & \multicolumn{3}{|c|}{ Fellow eye } \\
\hline & & & & & $\begin{array}{l}\text { Large } \\
\text { drusen }\end{array}$ & $\begin{array}{l}\text { Pigment } \\
\text { clumping }\end{array}$ & $\begin{array}{c}\text { RPE } \\
\text { atrophy }\end{array}$ \\
\hline 1 & 79 & 732 & $\mathrm{AL}$ & 732 & Yes & Yes & Yes \\
\hline 2 & 85 & 775 & IVR & 582 & No & Yes & Yes \\
\hline 3 & 81 & 1265 & PDT & - & Yes & Yes & Yes \\
\hline 4 & 58 & 1410 & PDT + IVTA & 1410 & Yes & No & No \\
\hline 5 & 85 & 845 & PDT & - & No & No & Yes \\
\hline 6 & 82 & 412 & IVR & - & Yes & Yes & Yes \\
\hline 7 & 61 & 909 & PDT & - & No & No & No \\
\hline 8 & 85 & 1123 & PDT + IVTA & 643 & No & Yes & Yes \\
\hline 9 & 75 & 1052 & PDT + IVTA, IVR & - & No & Yes & Yes \\
\hline 10 & 81 & 829 & IVR & - & No & Yes & Yes \\
\hline 11 & 83 & 683 & IVR & - & No & Yes & Yes \\
\hline 12 & 60 & 715 & IVR & - & No & No & No \\
\hline 13 & 86 & 745 & IVR & - & No & Yes & Yes \\
\hline 14 & 85 & 670 & IVR & - & No & Yes & Yes \\
\hline 15 & 84 & 1821 & PDT + IVTA & 1445 & No & Yes & Yes \\
\hline 16 & 68 & 1620 & PDT + IVTA & 1348 & Yes & Yes & Yes \\
\hline 17 & 84 & 1628 & PDT + IVTA & 234 & Yes & Yes & Yes \\
\hline 18 & 79 & 684 & IVR & - & Yes & Yes & Yes \\
\hline 19 & 66 & 828 & IVR & - & No & No & No \\
\hline 20 & 73 & 750 & PDT & - & No & Yes & Yes \\
\hline 21 & 79 & 746 & PDT & - & Yes & Yes & Yes \\
\hline 22 & 86 & 1701 & PDT & 876 & Yes & Yes & Yes \\
\hline 23 & 75 & 762 & PDT & - & No & Yes & Yes \\
\hline 24 & 63 & 1254 & PDT & - & No & Yes & Yes \\
\hline 25 & 86 & 538 & PDT + IVTA & - & No & No & Yes \\
\hline 26 & 80 & 1054 & IVR & - & Yes & Yes & Yes \\
\hline 27 & 88 & 916 & PDT & - & No & Yes & Yes \\
\hline 28 & 86 & 857 & PDT + IVTA & - & Yes & Yes & Yes \\
\hline 29 & 68 & 997 & PDT & - & No & No & No \\
\hline 30 & 86 & 640 & PDT + IVTA & - & No & Yes & Yes \\
\hline 31 & 85 & 863 & PDT + IVTA & - & No & Yes & Yes \\
\hline 32 & 89 & 546 & PDT + IVTA & - & No & No & No \\
\hline 33 & 71 & 1460 & PDT & 1334 & No & Yes & Yes \\
\hline 34 & 71 & 609 & PDT & - & No & Yes & Yes \\
\hline 35 & 85 & 945 & PDT + IVTA & - & Yes & Yes & Yes \\
\hline 36 & 75 & 1290 & PDT + IVTA & 314 & Yes & Yes & Yes \\
\hline 37 & 81 & 1242 & PDT + IVTA & - & Yes & Yes & Yes \\
\hline
\end{tabular}

Abbreviations: AL, argon laser; IVR, intravitreal ranibizumab; PDT, photodynamic therapy with verteporfin; IVTA, intravitreal triamcinolone acetonide; $\mathrm{RPE}$, retinal pigment epithelium.

These findings, if confirmed, would imply that patients with RAP should be followed more frequently than other patients with nAMD putting strain on services.

In our study, although performed on a smaller number of patients, we found a lower rate of incidence of RAP in the fellow eye. Differences in the study populations (ie, age, race and so on) could explain the discrepancy. It is also possible that the aggressive cases, who quickly became bilateral, only presented when the second eye was affected and therefore missed from this study. In our retrospective case series, in fact a considerable number of patients already had a disciform lesion in the fellow eye and therefore were excluded. However, the low incidence rate in the fellow eye found in the study prompt us to suppose that there may be a subset of patients in which the disease shows a lower tendency to bilaterality.

Another possible explanation could lie in the treatment received by the patients in their first eye in our case series. The risk of developing $\mathrm{CNV}$ in the fellow eye for patients receiving intravitreal injections of anti-VEGF drugs may be lower when compared with historic controls. ${ }^{14}$ It has been reported that anti-VEGF compounds can affect the uninjected eye with mechanisms not well elucidated but that may involve the escape of the molecule into the systemic circulation. ${ }^{15}$

The incidence of a neovascular lesion in the fellow eye in our series appears, however, higher than the $28 \%$ in 

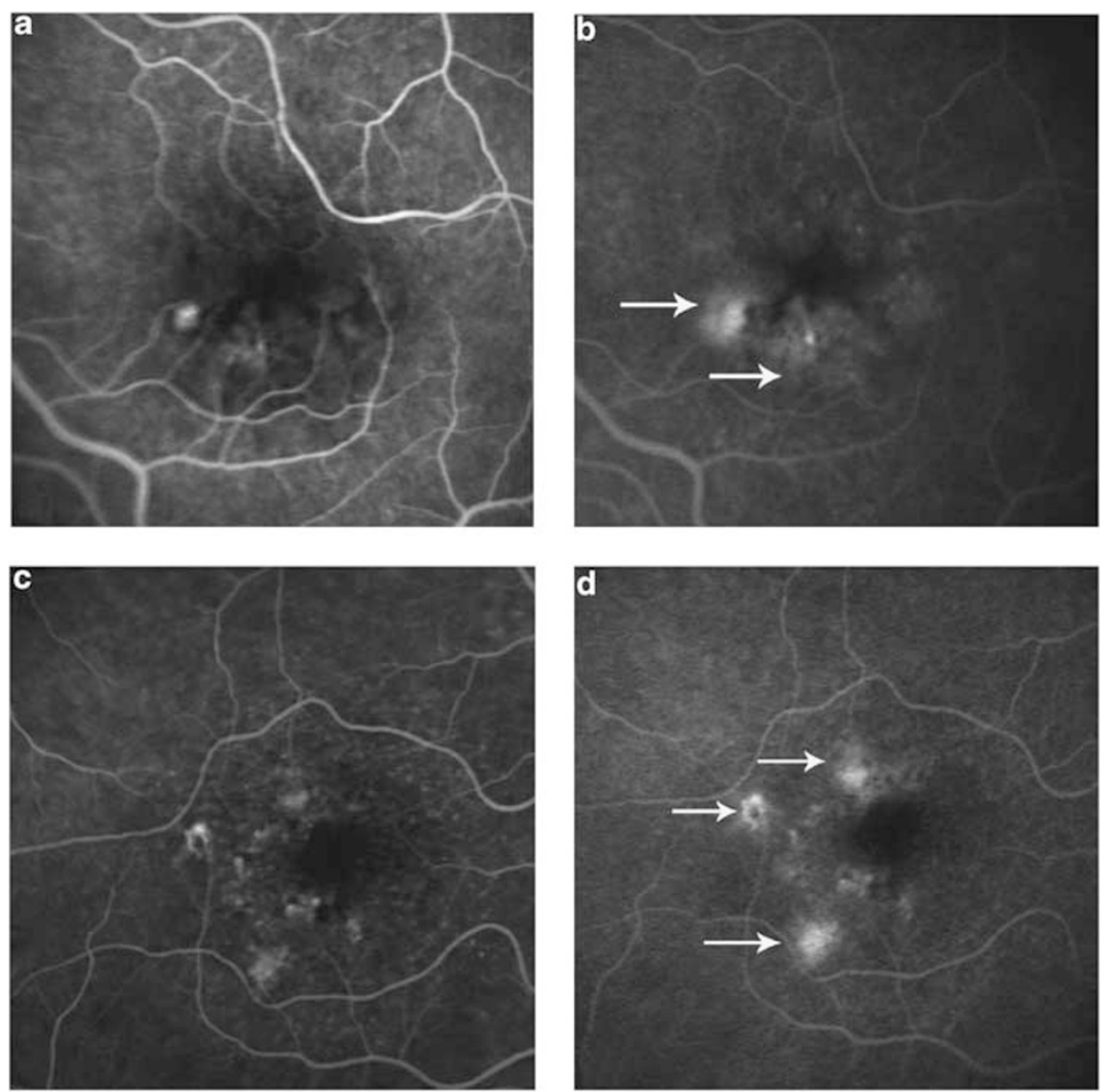

Figure 1 Early- (a) and late-phase (b) fluorescein angiography showing multifocal RAP in the first eye. The arrows indicate the foci. Early- (c) and late-phase (d) fluorescein angiography showing multifocal RAP in the fellow eye, which develop after 19 months of follow-up. The arrows indicate the foci.
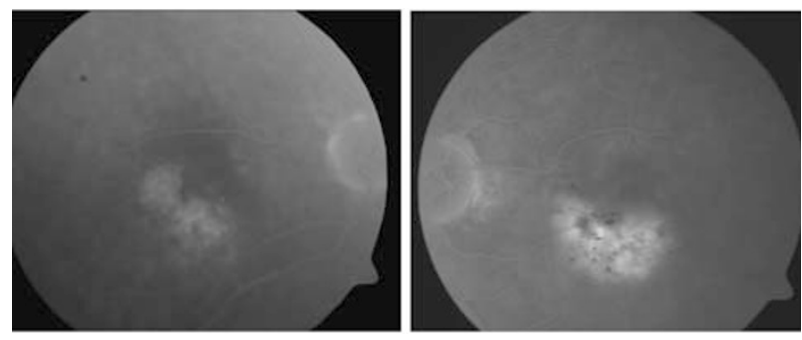

Figure 2 Late-phase fluorescein angiography showing bilateral symmetric RAP. Time between the lesions in the 2 eyes is 33 months.

3 years previously reported for standard CNV in the Macular Photocoagulation Study. ${ }^{16,17}$ This finding supports the fact that RAP is a more aggressive subgroup of nAMD.

Similar to previous reports, ${ }^{10}$ we found the neovascularization that develops in the fellow eye of these patients to be RAP in all our patients. Moreover, in our case series, $40 \%$ of the lesions in the fellow eyes appeared in the same retinal location as in the first eye. The only patient with a multifocal RAP in the fellow eye had the same type of lesion in the first eye.
Retinal pigment epithelial atrophy and focal hyperpigmentation were very common features in the fellow eyes developing RAP. Their presence may represent an important risk factor.

This study has several limitation related to the retrospective nature and the small number of patients. Overall, our findings show that RAP does not always involve both eyes, at least within a period of 3-4 years. Prospective studies with larger sample size and longer follow-up are needed to further explore the characteristics of this disease.

\section{Summary}

What was known before

- RAP is a bilateral disease in $100 \%$ of patients within 3 years.

\section{What this study adds}

- In our case series, the incidence of RAP in the fellow eye is much lower ( $36.4 \%$ at 3 years) compared with previous report. 


\section{Conflict of interest}

The authors declare no conflict of interest.

\section{Acknowledgements}

We thank David Parry and John Deane from the Liverpool Reading Centre for their valuable contribution in the analysis of angiograms.

\section{References}

1 Hartnett ME, Weiter JJ, Garsd A, Jalkh AE. Classification of retinal pigment epithelial detachments associated with drusen. Graefes Arch Clin Exp Ophthalmol 1992; 230: 11-19.

2 Yannuzzi LA, Negrão S, Iida T, Carvalho C, RodriguezColeman H, Slakter $\mathrm{J}$ et al. Retinal angiomatous proliferation in age-related macular degeneration. Retina 2001; 21: 416-434.

3 Freund KB, Ho IV, Barbazetto IA, Koizumi H, Laud K, Ferrara D et al. Type 3 neovascularization: the expanded spectrum of retinal angiomatous proliferation. Retina 2008; 28: 201-211.

4 Viola F, Massacesi A, Orzalesi N, Ratiglia R, Staurenghi G. Retinal angiomatous proliferation: natural history and progression of visual loss. Retina 2009; 29: 732-739.

5 Borrillo JL, Sivalingam A, Martidis A, Federman JL. Surgical ablation of retinal angiomatous proliferation. Arch Ophthalmol 2003; 121: 558-561.

6 Boscia F, Furino C, Sborgia L, Reibaldi M, Sborgia C. Photodynamic therapy for retinal angiomatous proliferations and pigment epithelium detachment. Am J Ophthalmol 2004; 138: 1077-1079.

7 Freund KB, Klais CM, Eandi CM, Ober MD, Goldberg DE, Sorenson JA et al. Sequenced combined intravitreal triamcinolone and indocyanine green angiography-guided photodynamic therapy for retinal angiomatous proliferation. Arch Ophthalmol 2006; 124: 487-492.
8 Johnson TM, Glaser BM. Focal laser ablation of retinal angiomatous proliferation. Retina 2006; 26: 765-772.

9 Lai TY, Chan WM, Liu DT, Lam DS. Ranibizumab for retinal angiomatous proliferation in neovascular age-related macular degeneration. Graefes Arch Clin Exp Ophthalmol 2007; 245: 1877-1880.

10 Gross NE, Aizman A, Brucker A, Klancnik Jr JM, Yannuzzi LA. Nature and risk of neovascularization in the fellow eye of patients with unilateral retinal angiomatous proliferation. Retina 2005; 25: 713-718.

11 Gass JD, Agarwal A, Lavina AM, Tawansy KA. Focal inner retinal hemorrhages in patients with drusen: an early sign of occult choroidal neovascularization and chorioretinal anastomosis. Retina 2003; 23: 741-751.

12 Monson DM, Smith JR, Klein ML, Wilson DJ. Clinicopathologic correlation of retinal angiomatous proliferation. Arch Ophthalmol 2008; 126: 1664-1668.

13 Yannuzzi LA, Freund KB, Takahashi BS. Review of retinal angiomatous proliferation or type 3 neovascularization. Retina 2008; 28: 375-384.

14 Barbazetto IA, Kumar K, Karamchandani H, Rabinowitz D, Takahashi B, Yannuzzi LA. Risk for choroidal neovascularization in the fellow eye of patients on anti-vegf therapy for neovascular age-related macular degeneration invest. Ophthalmol Vis Sci 2008; 49: 2227. E Abstract 256.

15 Rouvas A, Liarakos VS, Theodossiadis P, Papathanassiou M, Petrou P, Ladas I et al. The effect of intravitreal ranibizumab on the fellow untreated eye with subfoveal scarring due to exudative age-related macular degeneration. Ophthalmologica 2009; 223(6): 383-389.

16 Macular Photocoagulation Study Group. Five-year follow-up of fellow eyes of patients with age-related macular degeneration and unilateral extrafoveal choroidal neovascularization. Arch Ophthalmol 1993; 111: 1189-1199.

17 Macular Photocoagulation Study Group. Risk factors for choroidal neovascularization in the second eye of patients with juxtafoveal or subfoveal choroidal neovascularization secondary to age-related macular degeneration. Arch Ophthalmol 1997; 115: 741-747. 